\title{
Studies on the Surface and Optical Properties of Ta- Doped ZnO Thin Films Deposited By Thermionic Vacuum Arc
}

Suat Pat ( $\nabla$ suatpat@ogu.edu.tr)

Eskisehir Osmangazi Universitesi https://orcid.org/0000-0001-9301-8880

Reza Mohammadigharehbagh

Uludag Universitesi - Gorukle kampusu: Bursa Uludag Universitesi

Nihan Akkurt

Eskisehir Osmangazi Universitesi

Şadan Korkmaz

Eskisehir Osmangazi University: Eskisehir Osmangazi Universitesi

\section{Research Article}

Keywords: Ta doped ZnO, band gap, Raman spectra, crystallite size

Posted Date: April 15th, 2021

DOI: https://doi.org/10.21203/rs.3.rs-415794/v1

License: (9) This work is licensed under a Creative Commons Attribution 4.0 International License.

Read Full License 


\section{Abstract}

In this research, Ta doped $\mathrm{ZnO}$ thin films have been deposited onto glass and Si substrate by Thermionic vacuum arc (TVA) thin film deposition system. TVA is anodic plasma thin film deposition system and it is used to relatively high-quality thin films deposition. $\mathrm{ZnO}$ thin films have direct optical band gap of 3.37 $\mathrm{eV}$. Tantalum is an efficient higher-valance element. Ta atom gives the more electrons compared to Zinc atom and their ionic radius are very close to each other, so substituted element does not bring into additional stress in crystal network. The deposited thin films were analyzed by field emission scanning electron microscopy (FESEM), energy dispersive X-ray spectroscopy, atomic force microscopy, UV-Vis spectrophotometry and interferometer. To change the band gap properties of the $\mathrm{ZnO}$ thin film, Ta doping was used and band gap of Ta doped $\mathrm{ZnO}$ thin film was obtained $3.1 \mathrm{eV}$ by Tauc's method. The wt \% ratios for $\mathrm{Zn} / \mathrm{Ta}$ were calculated as 0.45 and 0.42 for the films deposited onto glass and Si substrate, respectively. Crystallite sizes of Ta doped $\mathrm{ZnO}$ thin film was decreased by changing substrate material. To the best of our knowledge, substituted Ta elements connected to the oxygen atom in crystal network and orthorhombic $\beta^{\prime}-\mathrm{Ta}_{2} \mathrm{O}_{5}$ were detected in the all films structure. Their band gaps of the $\beta^{\prime}-\mathrm{Ta}_{2} \mathrm{O}_{5}$ were measured as $2.70 \mathrm{eV}$ and $2.60 \mathrm{eV}$ for Ta-doped $\mathrm{ZnO}$ thin films deposited onto glass and Si substrate, respectively. Up to day, the band gap of the $\beta^{\prime}-\mathrm{Ta}_{2} \mathrm{O}_{5}$ was calculated by density function theory. According to results, $\beta^{\prime}-\mathrm{Ta}_{2} \mathrm{O}_{5}$ structure was found as embedded from in the $\mathrm{ZnO}$ crystal network.

\section{Introduction}

Zinc oxide $(\mathrm{ZnO})$ material has appealing tremendous attention in both researchers and industry groups owing to their transparency, large optical band gap (3.37 eV), the high exciton binding energy ( $60 \mathrm{meV})$ at room temperature as well as piezoelectricity properties [1]. This material is a combination of II-VI group semiconductors that formed mainly as hexagonal wurtzite structure, and well known as the best n-type semiconductor. The mentioned characteristics cause to emerging various application fields such as acoustic (resonator and wave) devices, sensors, solar cells, panel displays, thin film transistors, lightemitting diodes (LEDs) and detectors [2, 3]. Despite the application fields, by benefit of their non-toxicity, earth-abundant, high thermal stability, high oxidation resistance and low electron mobility using in harsh conditions and especially field emission devices also reported recently. Unfortunately, the main obstacles are poor conductivity, thermal treatment and stable p-type conductivity that restricted the spreading of area for application. Enhancing the conductivity of $\mathrm{ZnO}$ by different doping elements can lead to broadening utilizing of the material as the best candidate for the replacement of indium tin oxide (ITO). Indeed, the abundance and low-cost advantages of $\mathrm{ZnO}$ regarding indium result in attention as an alternative material by researchers [4]. According to the literature review, doping by $\mathrm{Al}, \mathrm{Ga}$ and $\ln [3,5]$ enable of reduction in the resistivity value of the $\mathrm{ZnO}$ but undesirably appear lattice deformation as well as of weakened oxidation resistance of the main material. However, doping with $\mathrm{N}, \mathrm{P}$ and $\mathrm{Sb}$ [6] elements already reasoned p-type $\mathrm{ZnO}$ that extent exploit it's in optoelectronics such as LED and detectors. Furthermore, doping with $\mathrm{Fe}, \mathrm{Mn}$ and $\mathrm{Co}$ [7] elements paved the way for using $\mathrm{ZnO}$ in spintronic annlications in liaht of ferromannetic features. 
The sol-gel, atomic layer deposition, magnetron sputtering, pulsed laser deposition, electrospraying, spray pyrolysis, molecular beam epitaxy and other methods have been carried out for the formation of $\mathrm{ZnO}$ as nanostructures or thin films [8-10]. In this research, far from the mentioned methods, a thermionic vacuum arc technique for coating Ta doped $\mathrm{ZnO}$ thin film was used. The glass and Si wafer were selected as substrates. The coating technique has a very high deposition rate that shortened the duration of coating coincide with a run in high vacuum conditions, eco-friendly (lack of using buffer or carrier gas inside the chamber during coating) and very low row material. A literature survey revealed a few researchbased on Ta doping on the $\mathrm{ZnO}$ structure that motivates to focus on doping the element and physical properties introduced by the element in the main $\mathrm{ZnO}$ structure despite amazing properties. Tantalum is a good candidate as a doping element for reaching an n-type semiconductor, it means, the element includes low-toxicity, chemical stability, high refractive index, cheap and low dangerous and hazardous advantageous beside of ionic radius value for substituting by $Z n$ in this structure [11]. Ta has known as $\mathrm{Ta}^{+5}$ instead of $\mathrm{Zn}^{+2}$ that logically introduces more electrons as carrier concentration to the structure, that is improves carrier concentration and increment impurity value at this route. It was noticed the amount of electron introduced by $\mathrm{Ta}$ is higher than $\mathrm{In}^{3+}, \mathrm{Al}^{3+}$ and $\mathrm{Ga}^{3+}$ elements which inferred using as Ta in a small value is fully enough for satisfying necessary carrier concentration along with a reduction in ion scattering in this structure. That means, enhancing the free carriers by entering a proper candidate such as Ta may be successfully reduce resistivity and gaining better optical characteristics for making a new application realm. The element has been frequently used in medical, electronics due to their high corrosion resistance, ductility, toughness, density, melting point and refractory materials. For instance, Ta thin films are extensively take a major role in microelectronics as a diffusion barrier between metals and Si substrates, as well as protect steel and glass-like materials when exposed to wear or corrosion [12].

In this research, Ta doped $\mathrm{ZnO}$ thin films have deposited onto glass and $\mathrm{Si}$ substrates by thermionic vacuum arc technique (TVA). The morphological, microstructure, electronic and optical properties of the thin film systematically performed using suitable devices. TVA is a physical vapor deposition technology. Deposited thin films were analyzed by field emission scanning electron microscopy, atomic force microscopy, Raman spectroscopy, interferometer and UV-Vis spectrophotometer. The surface and detailed optical properties of Ta doped $\mathrm{ZnO}$ thin films were determined. The $\beta^{\prime}-\mathrm{Ta}_{2} \mathrm{O}_{5}$ crystal properties were determined from the photoluminescence measurement $(\mathrm{PL})$ and Raman shift spectra. For the crystal properties $\beta^{\prime}-\mathrm{Ta}_{2} \mathrm{O}_{5} \mathrm{PL}$ and Raman shift spectra are deterministic method. Because, for the thin layer, $\mathrm{x}$ ray diffraction methods does has very low intensity for interference fringes.

\section{Materials And Method}

TVA method is a physical vapor deposition technology. Physical vapor deposition techniques work in vacuum conditions. TVA also is a plasma source and generates the pure material or alloy plasma. TVA system has two electrodes, these are anode and cathode. Anode is a tungsten boat and deposited materials (Ta slug and $\mathrm{ZnO}$ pellet) were placed inside of the boat. Cathode is an electron gun and it was conctruntod from tunncton filamont and W/ahnelt cylinder. In TVA, filament heated by AC high current. 
After the heating of the filament, emitted electrons accelerated towards to anode boat by DC high voltage. For TVA plasma generation, ignition voltage must be determined. The ignition voltage value relates with vapor pressure and melting pots of the materials. Firstly, the materials need energy for the evaporation interelectrodic space. Then, using by high DC voltage, TVA plasma generates in vacuum chamber [1-4]. In Table 1, TVA coating parameters are summarized.

Table 1

TVA coating parameters

\begin{tabular}{|llllll|}
\hline Parameter & $\begin{array}{l}\text { Discharge } \\
\text { current (A) }\end{array}$ & $\begin{array}{l}\text { Deposition } \\
\text { time (s) }\end{array}$ & $\begin{array}{l}\text { Working } \\
\text { pressure (torr) }\end{array}$ & $\begin{array}{l}\text { Applied } \\
\text { voltage }(\mathrm{V})\end{array}$ & $\begin{array}{l}\text { Filament } \\
\text { current (A) }\end{array}$ \\
\hline Value & 0.5 & 60 & $1 \times 10^{-4}$ & 450 & 18.5 \\
\hline
\end{tabular}

\section{Results And Discussion}

Ta doped ZnO thin films were deposited onto glass and Si substrate. The film thicknesses of the coated surface for glass and Si substrate are about $100 \mathrm{~nm}$ and $60 \mathrm{~nm}$, respectively. Before the deposition, substrate materials were cleaned by ethanol and deionized water. Field emission scanning electron microcopy (FESEM) analysis were done by Hitachi Regulus 8230 scanning electron microscopy. $10.0 \mathrm{kV}$ acceleration voltage and conductive coating were used obtain a good image. Obtained surface images for deposited films onto glass and Si substrate are shown in Fig. 1a and 1b, respectively. Crystallites for the film deposited onto Si substrate are bigger than the film deposited onto glass substrate and also crystallites are seen clearly in Fig. 1a and 1b.

EDS detector in Hitachi Regulus 8230 device was used for the elemental analysis. Obtained results are illustrated in Table 2. $\mathrm{Zn} / \mathrm{Ta}$ ration in wt \% for the films deposited onto substrates were found nearly close to each other. For the glass substrate, oxygen ratio is higher than the film deposited onto Si wafer.

Table 2

EDX analysis of the deposited thin film for glass and $\mathrm{Si}$ substrate

\begin{tabular}{|llllll|}
\hline $\begin{array}{l}\text { Element } \\
\text { Substrate }\end{array}$ & $\mathbf{0}$ & $\mathrm{Zn}$ & $\mathrm{Ta}$ & $\mathrm{Zn} / \mathrm{Ta}$ & Total \\
\hline Glass (wt\%) & 31.18 & 21.34 & 47.48 & 0.45 & 100 \\
\hline Si (wt\%) & 6.36 & 27.57 & 66.07 & 0.42 & 100 \\
\hline
\end{tabular}

Atomic force microscopy is a powerful tool to determine the surface properties of a nanostructured surface. A lot of properties of a surface can easily determine by AFM. An Ambios QScope AFM was used for the determination of the surface morphology. AFM images were obtained at room temperature in 10 umx10 um scale N.SC16 cantilever with $160 \mathrm{kHz}$ was used for the surface characterization. Scanning Loading [MathJax]/jax/output/CommonHTML/jax.js 
frequency was adjusted to $5 \mathrm{~Hz}$. Obtained AFM images for Ta doped $\mathrm{ZnO}$ thin film deposited onto glass and Si substarte are illustrated in Fig. $2 a$ and $2 b$. Surface homogeneity and distribution function of crystallites are the key parameters. These parameters can easily measure by AFM tool. Roughness of the film surface were measured as $20 \mathrm{~nm}$ and $8 \mathrm{~nm}$ for the film deposited onto glass and Si substrate, respectively. Although, the lowest roughness obtained for the film deposited onto Si substrate, the roughness of the film deposited onto glass substrate is very low compared the literature value, too. Distribution function of the crystallites height should be similar to Gauss function. It is show that the films have homogeny crystallite distribution onto surface. The height distribution function plots are illustrated in Fig. 2c. Compared the results, height of the crystallites deposited onto glass substrate is slightly bigger than the crystallites for $\mathrm{Si}$ substrate. The height distribution function plots are similar to gauss distribution function. Mean crystallites heights are approximately same and they were measured as $80 \mathrm{~nm}$ and $60 \mathrm{~nm}$, for glass or Si substrate, respectively. Skewness and Kurtosis values define the shape of the gauss function. Skewness values are 0.795 and 0.312 for the film deposited onto glass and Si substrate, respectively. Kurtosis values for the film deposited onto glass and Si substrate are 1.109 and 0.067 , respectively.

Raman spectroscopy is a non-destructive chemical analysis that portrays the lattice vibration of the material. Raman shift relates to molecular interactions, crystallinity, phase, chemical structure, etc. Renishaw inVia Raman Microscope was used for the analysis of the coated samples. The laser wavelength for Raman analysis is $532 \mathrm{~nm}$. Obtained results for the films deposited onto glass and $\mathrm{Si}$ wafer substrates are seen in Figs. $3 a$ and $3 b$. The analyses were done in the range of $400-4000 \mathrm{~cm}^{-1}$. The ZnO material has categorized as $C_{6 V}^{4}\left(\mathrm{P} 6_{3} \mathrm{mc}\right)$ space group [13]. It is well known the material belongs to a wurtzite structure that consists of eight different vibrational phonon modes in the Brillouin zone, it means:

$$
\Gamma=1 A_{1}+2 B_{1}+1 E_{1}+2 E_{2}
$$

1

in the above equation, the $\Gamma$ point is an indication of the Brillouin zone. Also, the $A_{1}$ and $E_{1}$ modes comprised of transverse and longitudinal optical which abbreviated as TO and LO, respectively. The $E_{2}$ mode is divided into the low and high-frequency phonon modes that assigned the vibrational modes of the $\mathrm{Zn}$ and $\mathrm{O}$ atoms in this structure. The $\mathrm{B}_{1}$ is a silent mode again include low and high frequencies modes, respectively. In our case, for analysis of the film deposited onto the glass substrate, two peaks at 553 and $1084 \mathrm{~cm}^{-1}$ were detected. The peaks emerged in $553 \mathrm{~cm}^{-1}$ assigned as $\mathrm{Zn}$ interstitial which was reported by other researchers $[14,15]$. Besides, the second peak is an indication of second-order longitudinal optical $E_{1}$ mode [16]. Furthermore, for the film deposited onto the Si wafer, the six main peaks were observed at $359,538,667,801,920$ and $1109 \mathrm{~cm}^{-1}$. In this substrate, the peaks present at 359,538 and $667 \mathrm{~cm}^{-1}$ are related to $E_{1}^{\text {high }}-E_{1}^{\text {low }}$, silent $B_{1}^{\text {high }}$ and two phonon processes of ZnO thin films [17], respectively. The two phonon process peak already reported by Samanta [18] and co-workers Loading [MathJax]/jax/output/CommonHTML/jax.js dary and highly concentrated Mn-doped ZnO thin films, on the 
other hand, Cheng et. al [19] similarly observed a Ce-rich layer in Ce-doped ZnO thin films, while Wang and co-workers [20] declared the peaks to fine $\mathrm{ZnO}$ powder to acoustic overtone by $\mathrm{A}_{1}$ symmetry. Moreover, the peaks at 801 and $920 \mathrm{~cm}^{-1}$ are representations of the two optical phonon (2LO) mode of amorphous tantalum oxide and asymmetric stretching of Si and oxygen bonds, respectively [21]. The final peak at $1109 \mathrm{~cm}^{-1}$ is attributed to the symmetry acoustic combination of $A_{1}$ and $E_{2}$ modes of Raman bands [22, 23]. Indeed, the Raman spectra have been executed for evaluation of the crystal disorders formation of thin films. In the all observed peaks on both substrates shifts to the higher wavenumber values were pronounced that giving rise to nano-crystalline behavior, stress because of Ta dopant and subsequently good adherence between the substrates and the produced films. According to the peaks that exist in Tadoped $\mathrm{ZnO}$ thin films on both glass and Si wafer substrates, the hexagonal wurtzite structure has been corroborated. The Raman spectra illustrated in Fig. 3a and 3b. Figure 3a and $3 \mathrm{~b}$ are similar to the spectra of the crystalline $\mathrm{Ta}_{2} \mathrm{O}_{5}$ and high temperature annealed coating samples [24].

Transmittance spectra of Ta doped ZnO thin films deposited onto glass substrate is seen in Fig. 4a. The reflectance of Ta doped $\mathrm{ZnO}$ thin films deposited onto glass and Si substrate are also illustrated in Fig. 4b. Measured spectra were recorded by Unico UV-Vis 4800 spectrophotometer. According to the Fig. 4a, transmittance of the film is very low, it is not transparent. Reflectance of the sample deposited onto glass substrate is bigger than the film deposited onto $\mathrm{Si}$ wafer substrate. For the film deposited onto Si substrate, reflectance value are nearly same in UV-Vis region at very low value $(\sim 2 \%)$. That is, Ta doped ZnO deposited onto Si wafer is a very good absorber for the UV-Vis region compared the film deposited onto glass substrate. The reflectance value for Ta doped $\mathrm{ZnO}$ thin film deposited onto glass substrate for $632 \mathrm{~nm}$ is approximately \%10.

Refractive indices, $n$ values of the samples were measured by Filmetrics F20 thin film thickness measurement device and refractive index via wavelength $(\mathrm{nm})$ graph is seen in Fig. 5a. All samples show the normal distribution for refractive index. $n$ values are decreasing with increasing wavelength $(\mathrm{nm})$. Mean $n$ value of the samples were determined as 1.95 at $600 \mathrm{~nm}$ for all samples deposited onto glass and Si wafer substrate. 1.95 value is an intersection point for the $n-\lambda(\mathrm{nm})$ graphs. For the film deposited onto glass substrate, $n$ value decreasing by increasing wavelength.

The band gap value of Ta doped ZnO thin films for glass and Si wafer substrate were calculated by optical method and photoluminescence tool. $\mathrm{ZnO}$ thin films is good candidate for the determination of the band gap of the material by using optical method. The optical model had use to amorphous semiconductors, but today's application field too boarding and it is used to nearly all semiconductors materials [25]. In this method, the optical absorbance values of the samples was measured by UV-Vis spectrophotometer and then plotted the absorbance coefficient, (ahu) $)^{1 / m}$ graph with respect to energy (hu). $a$ is calculated as following Eq. 2,

$a=2.303 \mathrm{~A} / \mathrm{t}(2)$ 
where, $\mathrm{A}$ is absorbance value and $\mathrm{t}$ is the thickness of the film. The bad gap calculation relation for optic model is given below in Eq. 3 [25];

$(\mathrm{ahu})^{1 / \mathrm{m}}=\mathrm{B}\left(\mathrm{hu}-\mathrm{E}_{\mathrm{g}}\right)(3$

where, $h$ is the Planck's constant, hu is the incident photon energy, $\mathrm{m}$ is the integer coefficient and its related with transition type of the semiconductor, $B$ is a constant and $E_{g}$ is the band gap of the semiconductor. A semiconductor has different type electron transition to conduction bang from the valance band. $m=1 / 2,3 / 2,2,3$ corresponds to direct allowed transitions, direct forbidden transitions, indirect allowed transitions, indirect forbidden transitions, respectively. For the $\mathrm{ZnO}, \mathrm{m}=1 / 2$ was determined from the optic model. Ta doped $\mathrm{ZnO}$ films show the similar behavior with un-doped $\mathrm{ZnO}$ semiconductor. To evaluate the band gap type, all $m$ values graphics should be plotted and compared the each other to better fit. Finally, the correct transitions can be determined by the graphs. Figure $5 \mathrm{~b}$ gives Ta doped $\mathrm{ZnO}$ thin films deposited onto glass substrate. Extrapolation of the (ahu $)^{1 / \mathrm{m}}$ - hu graph gave the $3.1 \mathrm{eV}$ for Ta doped $\mathrm{ZnO}$ thin film deposited onto glass substrate. The obtained values are good agreement with the related literature.

Photoluminescence (PL) spectra of Ta doped $\mathrm{ZnO}$ thin films deposited onto glass and Si substrate are given in Fig. 6. Tantalum is an efficient element for the higher valence element and substitution of $\mathrm{Ta}^{+\mathrm{x}}$ to $\mathrm{Zn}^{2+}$ sites in $\mathrm{ZnO}$ crystal network. After the substitution, TaOx formation should be detected in the crystal network. Most general oxide thallium phases are $\mathrm{TaO}_{2}$ and $\mathrm{Ta}_{2} \mathrm{O}_{5} . \mathrm{Ta}_{2} \mathrm{O}_{5}$ is an insulator with $4.3 \mathrm{eV}$ band gap. According to theoretical investigations and papers, different phase of $\mathrm{Ta}_{2} \mathrm{O}_{5}$ has the lowest bans gap. From Fig. 6, PL transitions at $2.70 \mathrm{eV}$ and $2.60 \mathrm{eV}$ of Ta doped $\mathrm{ZnO}$ thin films deposited onto glass and Si substrate, respectively. To the best of our knowledge, these band gap transitions are related with orthorhombic $\beta^{\prime}-\mathrm{Ta}_{2} \mathrm{O}_{5}$ [26]. The crystal structures of $\mathrm{Ta}_{2} \mathrm{O}_{5}$ are formed in orthorhombic, tetragonal, hexagonal metastable form. The band gap of the $\beta^{\prime}-\mathrm{Ta}_{2} \mathrm{O}_{5}$ was calculated by density function theory and results are appropriate our findings. According to results, $\beta^{\prime}-\mathrm{Ta}_{2} \mathrm{O}_{5}$ structure embedded in the $\mathrm{ZnO}$ crystal network. Ta ions substituted $\mathrm{Zn}^{+2}$ ions in crystallite network of Ta doped $\mathrm{ZnO}$ semiconductors. So, it is investigated the surface and optical properties of the $\beta^{\prime}-\mathrm{Ta}_{2} \mathrm{O}_{5}$ embedded $\mathrm{ZnO}$ thin film.

\section{Conclusion}

Ta doped $\mathrm{ZnO}$ thin films have been deposited onto glass and Si substrate by thermionic vacuum arc (TVA) technology. Ta doped $\mathrm{ZnO}$ is not research very well compared the other research paper about doped $\mathrm{ZnO}$. Generally, optical properties of the doped $\mathrm{ZnO}$ are interested in research for the semiconductor applications. Un-doped ZnO has indirect band gap of $3.37 \mathrm{eV}$. Surface morphology of the deposited thin films were analyzed by field emission scanning electron microscopy (FESEM). Crystallites sizes for the thin film deposited onto Si substrate are bigger than the film deposited onto glass substrate. The weight percentage of $\mathrm{Zn} / \mathrm{Ta}$ for the deposited films were obtained 0.45 and 0.42 , respectively. 
$\mathrm{nm}$, respectively. Roughness of the film surface were measured as $20 \mathrm{~nm}$ and $8 \mathrm{~nm}$ for the film deposited onto glass and Si wafer, respectively. The peaks present at 359, 538 and $667 \mathrm{~cm}^{-1}$ are related to $E_{1}^{\text {high }}-E_{1}^{\text {low }}$, silent $B_{1}^{\text {high }}$ and two phonon processes of $\mathrm{ZnO}$ thin films. The deposited film are opac in UV-Vis spectral region. Refractive indices value of the samples were determined as 1.95 at $600 \mathrm{~nm}$. According to the optical plot and calculations, Ta doped $\mathrm{ZnO}$ thin film has $3.1 \mathrm{eV}$ and direct allowed transition semiconductor. Ta ions substituted $\mathrm{Zn}^{+2}$ ions in crystallite network of Ta doped $\mathrm{ZnO}$ semiconductors. Finally, TVA is a simple technology to obtain the doping semiconductor material.

\section{References}

1. Mohammadigharehbagh, R., Özen, S., Yudar, H.H., Pat, S., Korkmaz, Ş: The electrical, elemental, optical, and surface properties of Si-doped $\mathrm{ZnO}$ thin films prepared by thermionic vacuum arc. Materials Research Express. 4(9), 096404 (2017). https://doi.org/10.1088/2053-1591/aa7a6b

2. Mohammadigharehbagh, R., Pat, S., Musaoglu, C., Korkmaz, Ş, Özen, S.: The investigation of the $\mathrm{Cr}$ doped $\mathrm{ZnO}$ thin films deposited by thermionic vacuum arc technique. Materials Research Express. 5(2), 026403 (2018). https://doi.org/10.1088/2053-1591/aaab90

3. Mohammadigharehbagh, R., et al.: Investigation of the optical properties of the indium-doped $\mathrm{ZnO}$ thin films deposited by a thermionic vacuum arc. Optik 157, 667-674 (2018)

4. Mohammadigharehbagh, R., Pat, S., Özen, S., Yudar, H.H., Korkmaz, Ş: Investigation of the optical properties of the indium-doped $\mathrm{ZnO}$ thin films deposited by a thermionic vacuum arc. Optik. 157, 667-674 (2018). https://doi.org/10.1016/j.ijleo.2017.11.102

5. Pat, S., Mohammadigharehbagh, R., Özen, S., Şenay, V., Yudar, H.H., Korkmaz, Ş: The Al doping effect on the surface, optical, electrical and nanomechanical properties of the $\mathrm{ZnO}$ and AZO thin films prepared by RF sputtering technique. Vacuum. 141, 210-215 (2017). https://doi.org/10.1016/j.vacuum.2017.04.025

6. Paradowska, K.M., Przeździecka, E., Płaczek-Popko, E., Zielony, E., Stachowicz, M., Kozanecki, A.: Effect of annealing on photoluminescence and Raman scattering of Sb-doped ZnO epitaxial layers grown on a-Al203. J. Alloy. Compd. 774, 1160-1167 (2019). https://doi.org/10.1016/j.jallcom.2018.09.379

7. Sree, D.N., Deborrah, S.P.M., Gopinathan, C., Inbanathan, S.S.R.: Enhanced UV light induced photocatalytic degradation of Methyl Orange by Fe doped spray pyrolysis deposited ZnO thin films. Appl. Surf. Sci. 494, 116-123 (2019). https://doi.org/10.1016/j.apsusc.2019.07.091

8. Tao, K., Yi, H., Tang, L., Wu, J., Wang, P., Wang, N., ... Chang, H.: Piezoelectric ZnO thin films for 2DOF MEMS vibrational energy harvesting. Surface and Coatings Technology. 359, 289-295 (2019). https://doi.org/10.1016/j.surfcoat.2018.11.102

9. Pérez-González, M., Tomás, S.A., Santoyo-Salazar, J., Gallardo-Hernández, S., Tellez-Cruz, M.M., Solorza-Feria, O.: Sol-gel synthesis of Ag-loaded TiO2-ZnO thin films with enhanced photocatalytic activitv. J. Allov. Compd. 779. 908-917 (2019). https://doi.org/10.1016/j.jallcom.2018.11.302 
10. Adachi, Y., Saito, N., Sakaguchi, I., Suzuki, T.T.: Polarity dependent gas sensing properties of ZnO thin films. Thin Solid Films. 685, 238-244 (2019). https://doi.org/10.1016/j.tsf.2019.06.023

11. Shiri, S., Odeshi, A., Chen, N., Feng, R., Sutarto, R., Yang, Q.: FCC tantalum thin films deposited by magnetron sputtering. Surface and Coatings Technology. 358, 942-946 (2019). https://doi.org/10.1016/j.surfcoat.2018.12.015

12. Bunting, A., Cheung, R.: Evaluation of residual stress in sputtered tantalum thin-film. Appl. Surf. Sci. 371, 571-575 (2016). https://doi.org/10.1016/j.apsusc.2016.02.236

13. Tripathi, N., Vijayarangamuthu, K., Rath, S.: A Raman spectroscopic study of structural evolution of electrochemically deposited ZnO films with deposition time. Mater. Chem. Phys. 126(3), 568-572 (2011). https://doi.org/10.1016/j.matchemphys.2011.01.026

14. Exarhos, G.J., Sharma, S.K.: Influence of processing variables on the structure and properties of ZnO films. Thin Solid Films. 270(1-2), 27-32 (1995). https://doi.org/10.1016/0040-6090(95)06855-4

15. Saw, K.G., Ibrahim, K., Lim, Y.T., Chai, M.K.: Self-compensation in ZnO thin films: An insight from X-ray photoelectron spectroscopy, Raman spectroscopy and time-of-flight secondary ion mass spectroscopy analyses. Thin Solid Films. 515(5), 2879-2884 (2007). https://doi.org/10.1016/j.tsf.2006.08.047

16. Jothilakshmi, R., Ramakrishnan, V., Thangavel, R., Kumar, J., Sarua, A., Kuball, M.: (2009). MicroRaman scattering spectroscopy study of Li-doped and undoped ZnO needle crystals. Journal of Raman Spectroscopy: An International Journal for Original Work in all Aspects of Raman Spectroscopy, Including Higher Order Processes, and also Brillouin and Rayleigh Scattering, 40(5), 556-561. https://doi.org/10.1002/jrs.2164

17. Yahia, S.B., Znaidi, L., Kanaev, A., Petitet, J.P.: Raman study of oriented ZnO thin films deposited by sol-gel method. Spectrochim. Acta Part A Mol. Biomol. Spectrosc. 71(4), 1234-1238 (2008). https://doi.org/10.1016/j.saa.2008.03.032

18. Samanta, K., Dussan, S., Katiyar, R.S., Bhattacharya, P.: Structural and optical properties of nanocrystalline Zn 1 - x Mn x O. Appl. Phys. Lett. 90(26), 261903 (2007). https://doi.org/10.1063/1.2751593

19. Cheng, B., Xiao, Y., Wu, G., Zhang, L.: The vibrational properties of one-dimensional ZnO: Ce nanostructures. Applied physics letters. 84(3), 416-418 (2004). https://doi.org/10.1063/1.1639131

20. Wang, R.P., Xu, G., Jin, P.: Size dependence of electron-phonon coupling in ZnO nanowires. Phys. Rev. B. 69(11), 113303 (2004). https://doi.org/10.1103/PhysRevB.69.113303

21. Gritsenko, V.A., Volodin, V.A., Perevalov, T.V., Kruchinin, V.N., Gerasimova, A.K., Aliev, V.S., Prosvirin, I.P.: Nanoscale potential fluctuations in nonstoichiometrics tantalum oxide. Nanotechnology. 29(42), 425202 (2018). https://doi.org/10.1088/1361-6528/aad430

22. Ojha, A.K., Srivastava, M., Kumar, S., Hassanein, R., Singh, J., Singh, M.K., Materny, A.: Influence of crystal size on the electron-phonon coupling in $\mathrm{ZnO}$ nanocrystals investigated by Raman spectroscopy. Vib. Spectrosc. 72, 90-96 (2014). https://doi.org/10.1016/j.vibspec.2014.02.013 
24. Joseph, C., Bourson, P., Fontana, M.D.: Amorphous to crystalline transformation in Ta205 studied by Raman spectroscopy. J. Raman Spectrosc. 43(8), 1146-1150 (2012). https://doi.org/10.1002/jrs.3142

25. Viezbicke, B.D., Patel, S., Davis, B.E., Birnie, I.I.I., D. P: Evaluation of the Tauc method for optical absorption edge determination: ZnO thin films as a model system. physica status solidi (b). 252(8), 1700-1710 (2015). https://doi.org/10.1002/pssb.201552007

26. Hollerweger, R., Holec, D., Paulitsch, J., Bartosik, M., Daniel, R., Rachbauer, R.,... Mayrhofer, P. H. (2015). Complementary ab initio and X-ray nanodiffraction studies of Ta205. Acta materialia, 83, 276-284. https://doi.org/10.1016/j.actamat.2014.10.006

\section{Figures}

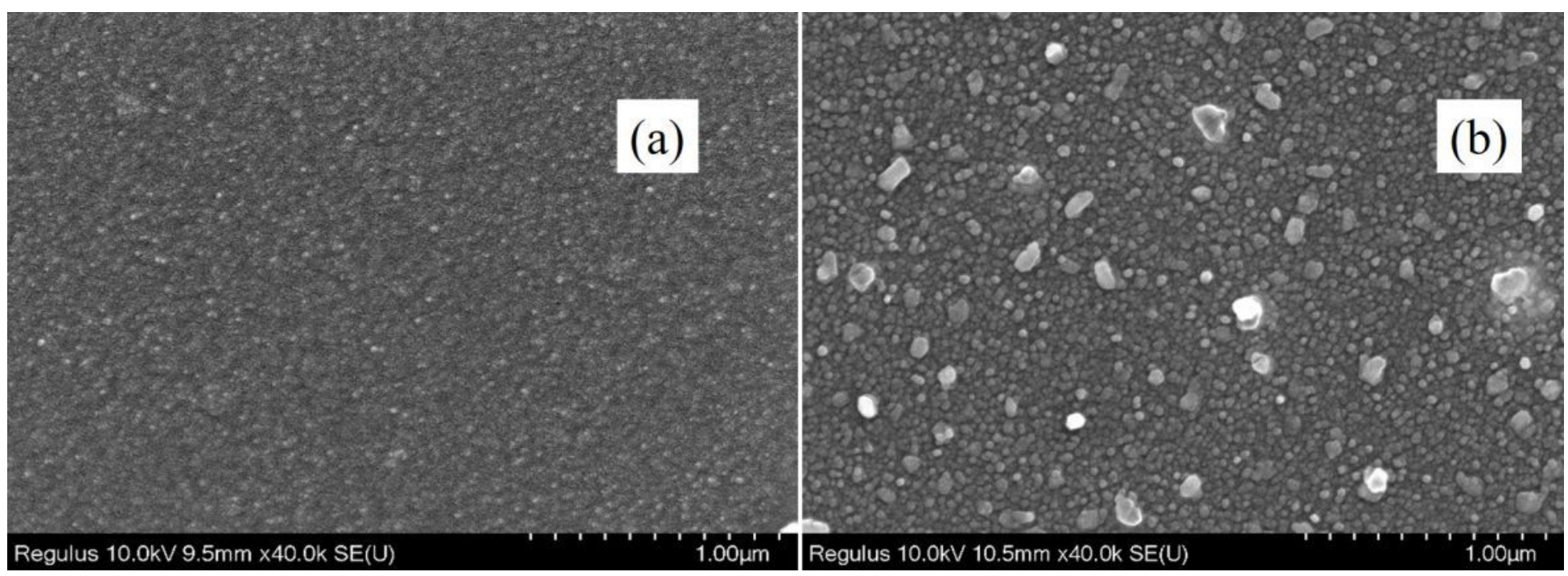

Figure 1

FESEM images of the deposited thin films onto (a) glass and (b) Si substrate 

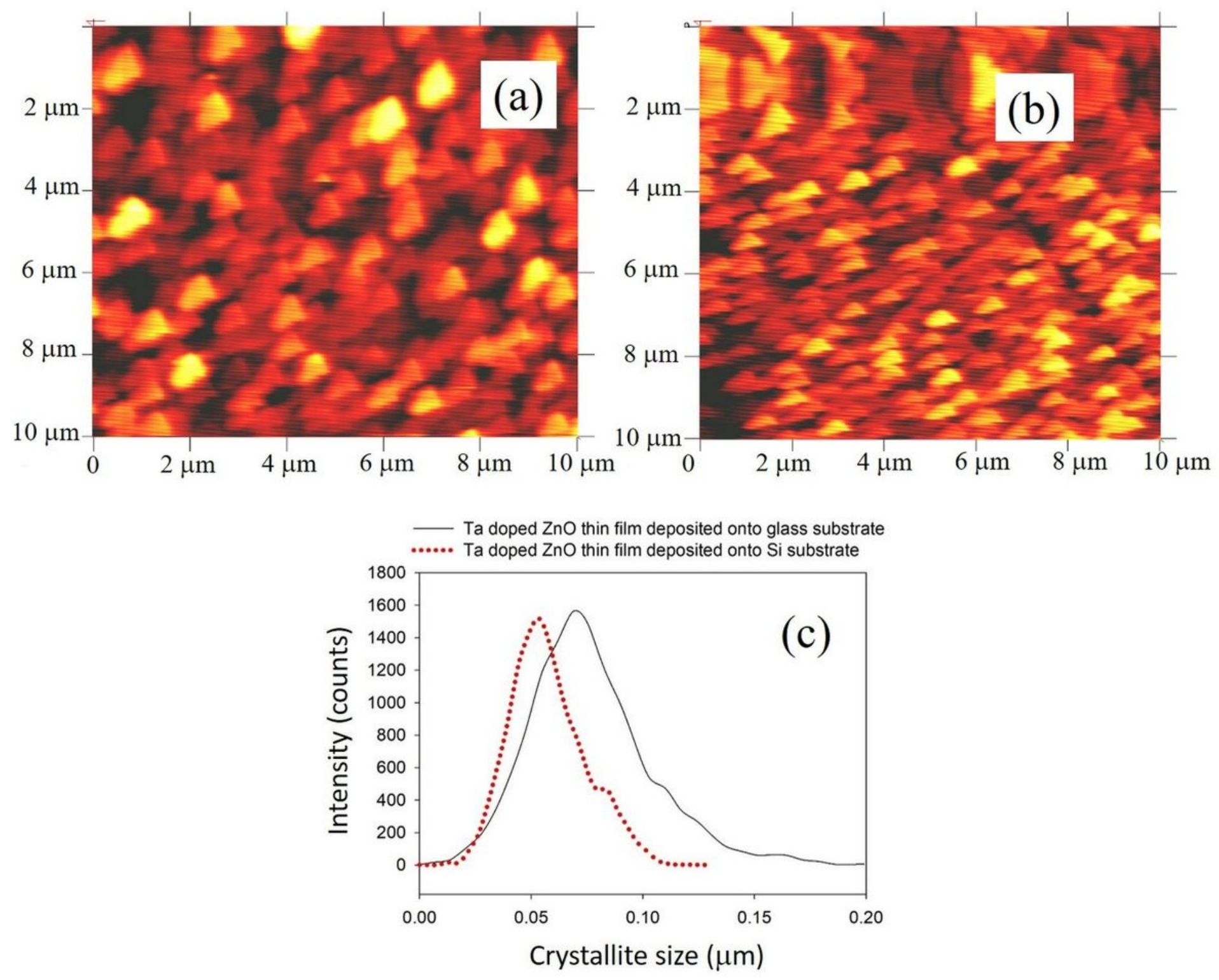

Figure 2

AFM images of the depoited thin films onto (a) glass and (b) Si substrate. (c) Compatative graphs of the crystallite sizes of the deposited films. 

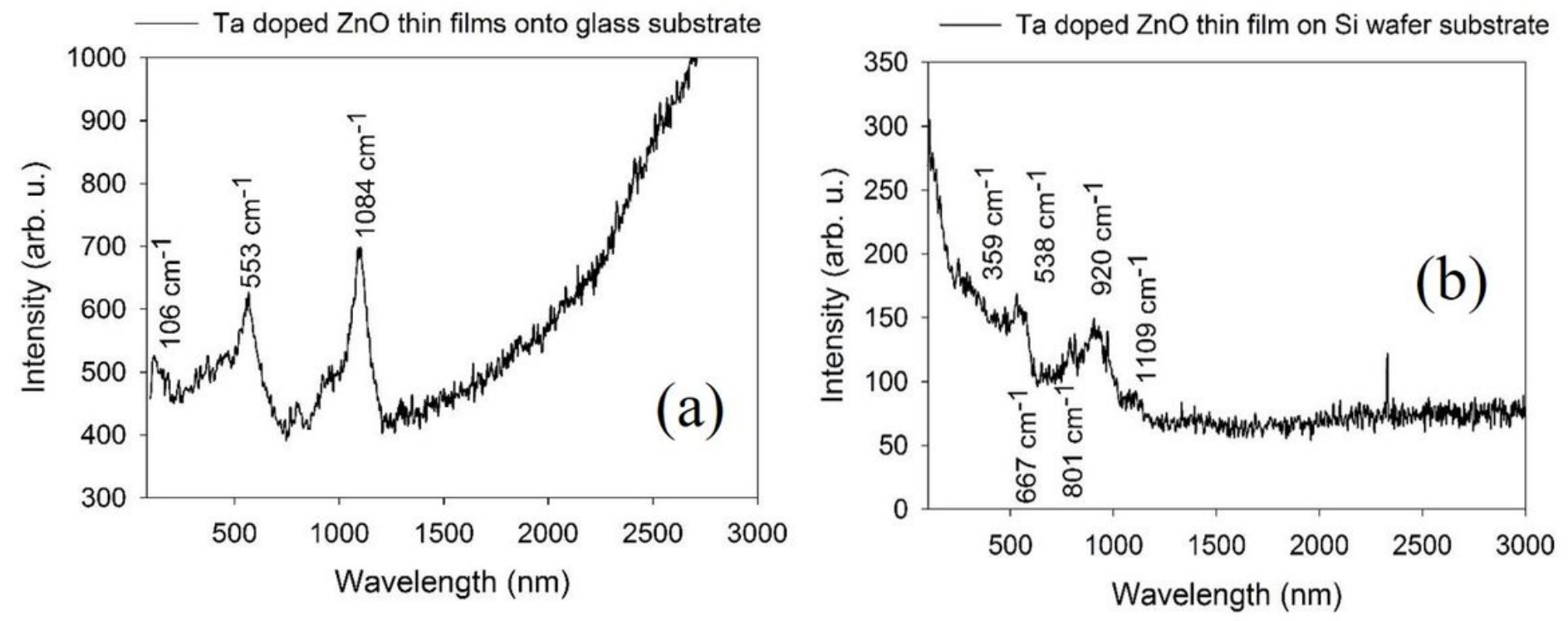

Figure 3

Raman graphs of Ta doped ZnO thin films for (a) glass and (b) Si substrate
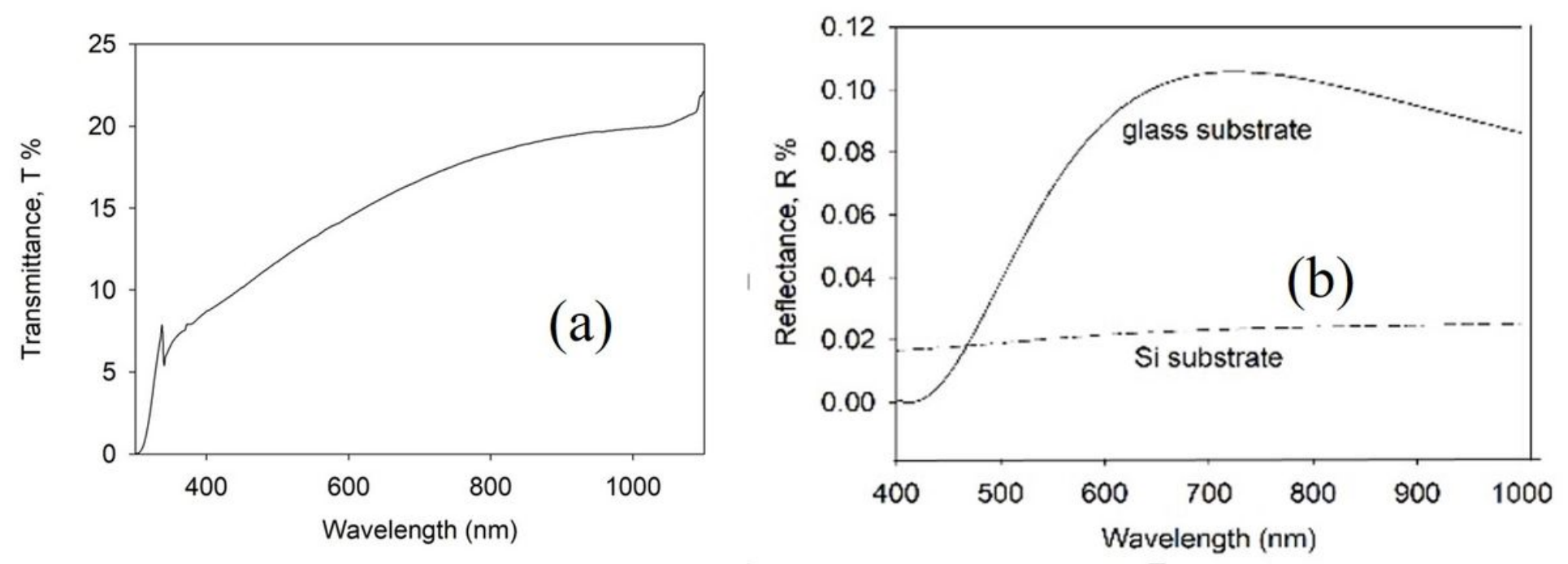

Figure 4

(a) Transmittance and (b) reflectance spectra of Ta doped ZnO thin films deposited onto glass and Si substrate 

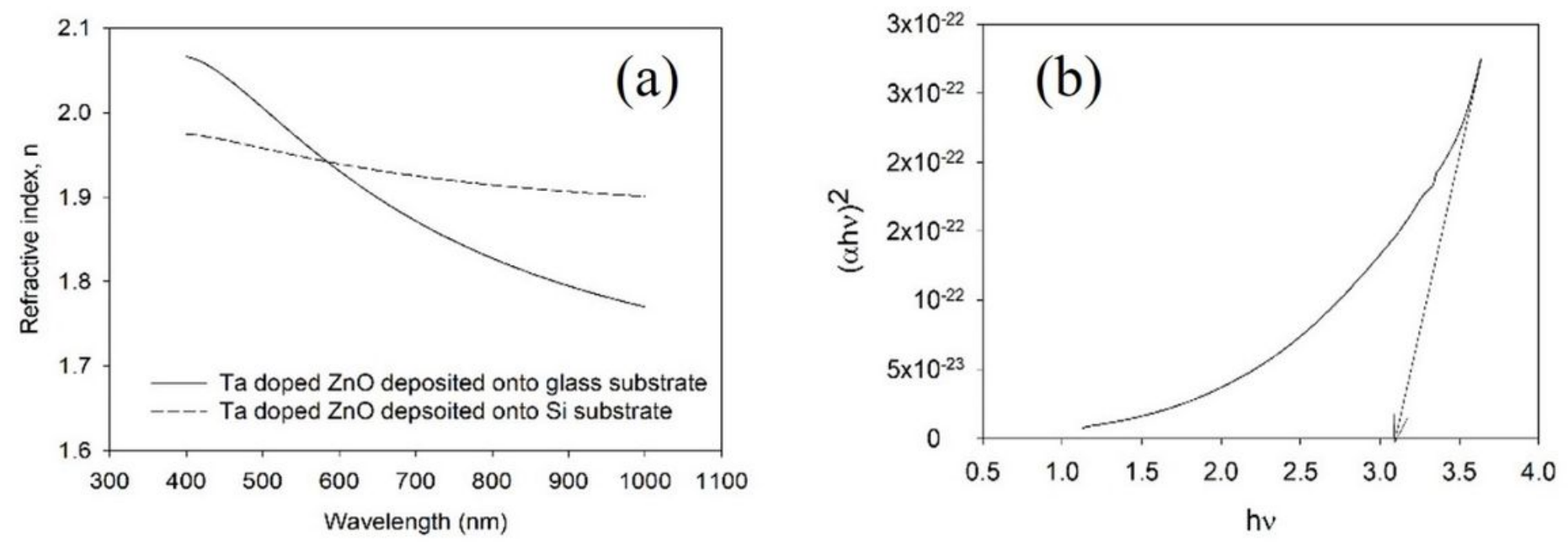

Figure 5

(a) Refractive index and (b) band gap plot of Ta doped $\mathrm{ZnO}$ thin films deposited onto glass and $\mathrm{Si}$ substrate

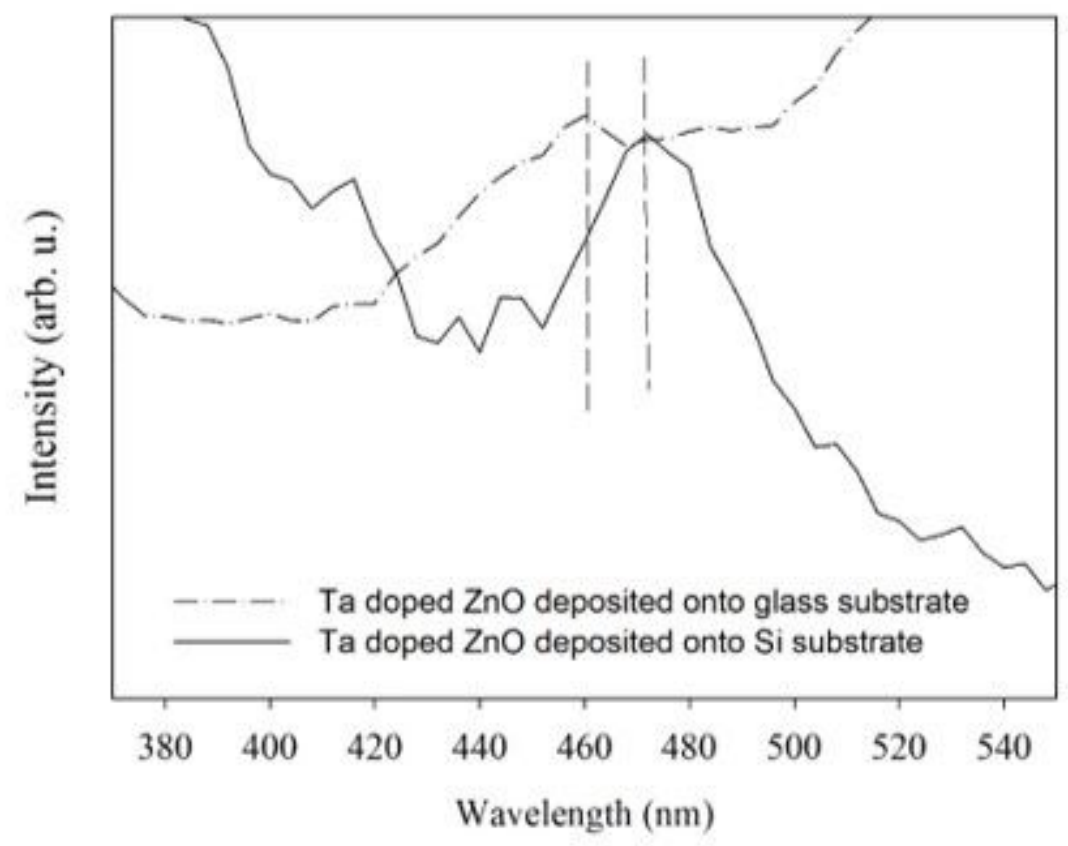

Figure 6

Photoluminescence spectra of Ta doped $\mathrm{ZnO}$ thin films deposited onto glass and Si substrate 